\title{
Lemon Tree Hotels: managing business during COVID-19
}

\author{
Chetan Joshi • Rita Karmakar
}

Accepted: 11 November 2021/Published online: 15 December 2021

(C) The Author(s) under exclusive licence to Indian Institute of Management Calcutta 2021

\begin{abstract}
On 30 January 2020, the Director General of World Health Organization declared the novel coronavirus outbreak (2019-nCov) [hereafter COVID] as a Public Health Emergency of International Concern. By 7 March 2020, global tally of reported COVID cases had crossed 1,00,000. Taking cognizance of the situation and to stem the increase in the number of cases, India went to a 21-day lockdown on 25 March 2020. Lemon Tree Hotels (LTH), India's largest mid-priced Indian hotel chain, with 84 hotels in 51 destinations with 8300 rooms and over 8000 employees, was expected to be impacted. This case study highlights the challenges LTH faced during lockdown and unlock period. It also highlights the strategies adopted by LTH leadership to keep in mind the interests of their stakeholders and keep the business afloat during the pandemic.
\end{abstract}

Keywords COVID-19 - Lemon Tree Hotels · Leadership in a pandemic $\cdot$ Lockdown

C. Joshi

Indian Institute of Management Calcutta, Kolkata, India e-mail: chetan@iimcal.ac.in

\section{R. Karmakar $(\bowtie)$}

Amity Institute of Psychology and Allied Sciences, Amity

University, Kolkata, India

e-mail: rkisical80@gmail.com

\section{Introduction}

In December 2019, COVID appeared in Wuhan, China. On 30 January 2020, the Director General of WHO declared COVID as a Public Health Emergency of International Concern. As of 29 July 2021, the World Health Organization COVID (World Health Organization n.d.) dashboard reported more than 195,886,929 confirmed cases and 4,189,148 deaths. As on 28 July 2021, a total of $3,830,124,730$ people received vaccination. In India, Kerala reported the first case of COVID on 30 January 2020. COVID, a highly infectious virus, created panic in the minds of the population. A "Janata Curfew" (people's curfew) was announced for 22 March 2020 (Chandna and Basu, 2020). Later, Government of India declared nationwide lockdown in four phases starting from 25 March 2020. The unlock phases started from 1 June 2020 (Soni 2021). Lockdown and unprecedented travel restrictions directly impacted the hospitality sector. With stay-at-home orders, social distancing, travel and mobility restrictions, all types of bookings for hotelscorporate, retail, leisure, meeting, events and conferences-got cancelled or postponed during latter part of Q4FY20 and first two quarters of FY21. The leadership team of Lemon Tree hotels (LTH), a mid-priced Indian hotel chain Patanjali Keswani started in early 2000s, had to devise strategies to keep the business afloat during the pandemic. 
Using LTH as a case study, we describe the role of leadership in managing business during a pandemic. We draw data from secondary sources such as articles on LTH on the world wide web, media coverage and annual reports available on LTH's website and YouTube videos featuring members of LTH top management team.

\section{COVID}

COVID emerged in Wuhan, China, in December 2019. This highly contagious virus could purportedly spread through inhalation of airborne particles or contact with asymptomatic individuals or touching of contaminated inanimate surfaces on which the virus could purportedly survive for long periods. As it became a pandemic, ${ }^{1}$ the suggested approaches to reduce transmission included: social distancing (keeping a distance of at least one metres), frequent hand washing, sanitization, wearing of face masks in public and increased ventilation of erstwhile closed spaces. Many cities/nations imposed varying degrees of lockdown. With no effective cure/medicine available and reeling under the social isolation due to the lockdown, COVID also brought in increased levels of stress and anxiety. Research findings revealed that as on June 2020, $40 \%$ of US adults experienced negative mental health symptoms, with $11 \%$ having suicidal ideation (Czeisler et al. 2020). An online Indian survey reported that about $40.5 \%$ of the participants reported anxiety or depressive symptoms and about $74.1 \%$ of the participants reported a moderate level of stress, and $71.7 \%$ reported poor well-being (Grover et al. 2020). Spending most of the time at home had increased excessive use of internet and excessive watching of television which may lead to technology addiction (Dixit et al. 2020; Zandifar and Badrfam, 2020). According to UNESCO (2020), approximately 0.32 billion students in India were affected by school closures due to the COVID-19 pandemic. There were also media reports of stigmatization of frontline workers across occupations. In some nations, Chinese people and Chinese restaurants faced discrimination. Initial measures like contact tracing and words like

\footnotetext{
$\overline{1}$ Pandemic is a worldwide outbreak of a new disease.
}

super-spreaders also led to use of stigmatizing language (e.g. COVID suspect).

The global economy bore the brunt of the raging pandemic. In 2020, the GDP of China, France, Spain and Italy fell by $36.6 \%, 21.3 \%, 19.2 \%$ and $17.5 \%$, respectively (The Indian Express 2020). COVID-19 has had a devastating impact on India's GDP as well. The GDP for the April-June 2021 (Q1) quarter dropped by $23.9 \%$ in comparison with Q1 quarter of 2020 (Economy 2020). The Indian economy saw the first impact during January-March 2020. With complete lockdown enforced from 25 March 2020, domestic as well as international travel was badly hit with immediate impact on the hotel industry in India.

\section{Lemon Tree Hotels (LTH)}

Founded in early 2000s by Patanjali Keswani, LTH was India's largest and award winning mid-priced hotel chain (see Appendix 1 for LTH's mission, vision and core values). LTH operated across a wide range of segments such as upscale segment, upper mid-scale, mid-scale and economy. In 2018, LTH was listed on the National Stock Exchange. As of 2019, it operated 8300 rooms (room-to-staff ratio of 1:1) at 84 hotels across 51 cities under various brands like Aurika Hotels and Resorts, Lemon Tree Premier (LTP), Lemon Tree Hotels (LTH), Red Fox Hotels (RFH), Keys Prima, Keys Select and Keys Lite. By 2022, LTH planned to be present in 68 cities in India and abroad with 10,765 rooms in 109 hotels (Annual Report 2019-20, Lemon Tree Hotels Limited, p. 5). Lemon Tree Hotels operated in most of the metro regions, as well as tier I and tier II cities such as Pune, Ahmedabad, Chandigarh, Jaipur, Indore, Aurangabad, Udaipur, Visakhapatnam, Kochi, Ludhiana, Thiruvananthapuram and Vijayawada. In December 2019, the company expanded globally with the launch of a hotel in Dubai and another in Bhutan two months later.

At LTH, Keswani was instrumental in creating an inclusive environment by offering opportunities to people with disabilities (visual and hearing impaired, autistic, Down's syndrome) and Opportunity Deprived Indians (Amazing Workplace Bureau 2019). 20\% of LTH employees (more than 1000 employees) were from the disadvantaged (transgenders, acid attack survivors, economically weaker section and educationally backward section) segment of the population 
(Lal n.d.). By 2021, LTH expected to have 25\%-30\% opportunity deprived individuals in their workforce (BW Hotelier 2018). For its unique initiatives, LTH received many awards and accolades such as "Best Employer of Persons with Disabilities" in 2011 and 2016; National Award in 2012 for being a "Role Model" in providing a Barrier Free Environment to Persons with Disabilities (Lemon Tree Hotels n.d.).

LTH developed a unique career progression plan for all employees so that everyone got a fair chance to be promoted. LTH closely monitored the performance of employees and then classified them into categories such as High Performers and Super High Achievers and promoted employees based on their overall performance. LTH created a culture to serve guests with friendly smile and cheerful greetings. The friendly environment also provided a psychologically safe and home-like experience to guests. They also provided banquet halls, meeting and conference rooms to accommodate family party, conference and office meetings. Not only psychological security but also physical security was primary focus at LTH. They upgraded the security system with updated technology such as $3 \mathrm{D}$ walkthrough, cameras powered by facial recognition software and intruder alarm.

In order to increase guest satisfaction, LTH not only provided better offerings at competitive prices but also arranged refresher courses for employees in order to upgrade their knowledge and to retain best practices across the hotels. LTH's stable hotels (functional for 3 years or more) experienced occupancy level of $79.2 \%$ in FY19. Through its partnership with Warburg Pincus, LTH planned to offer co-living accommodation and student housing for migrant employees and students across the country. The company's total income increased by $13.7 \%$ from Rs. 49,207 lakhs during the fiscal year 2018 to Rs. 55,944 lakhs during the fiscal year 2019 (Annual Report 2019-20, Lemon Tree Hotels Limited, p.33).

\section{LTH during lockdown}

On 25 March 2020, nationwide lockdown and social distancing were enforced in order to prevent the spread of COVID-19. Travel restrictions and social distancing created a big challenge for the tourism and hospitality sector. Offices, hotels, restaurants, bars, shops, malls, transportation and almost everything except very few essential services closed instantly. Hotel business was capital-intensive with high fixed costs. A significant portion of revenue came as operating revenue. The initial days of lockdown were extremely challenging for LTH as it was confronted with the possibility of almost zero occupancy in most of the hotels. Keswani (money control 2020) noted:

"Earlier Indian hospitality industry was on average witnessing 65 per cent to 70 per cent or full occupancy till the end of the February. First few days of the March were fine, once the things (spread of COVID) started accelerating, the occupancy has gone down to a minimum".

In FY19, the occupancy rates for Lemon Tree Premier (LTP), Lemon Tree Hotel (LTH) and Red Fox Hotel (RFH) were $78.4 \%, 74.3 \%$ and $77.6 \%$ respectively. In FY 20, the occupancy rates for all these segments (for LTP, LTH and RFH occupancy rates were $75.7 \%, 72.2 \%$ and $73.3 \%$, respectively) dropped significantly (see Fig. 1 from Annual Report 2019-20, Lemon Tree Hotels Limited p.18 and Annual Report 2018-19, Lemon Tree Hotels Limited p.8). In May 2020, due to partial lifting of lockdown in some states, $78 \%$ of its rooms became operational. The occupancy in hotels was close to $40 \%$ with much lower average room rates (ARRs) ${ }^{2}$ than the pre-lockdown period. All food and beverage outlets along with its banquet business remained shut, in-room dining remained operational.

As per the consolidated financial results (Value Stocks n.d.), total income decreased from 203.47 crores (October 2019-December 2019) to 177.28 crores (January 2020-March 2020) [see Table 1]. LTH needed to ride out the difficulties COVID had brought. It had to keep in mind the various stakeholders who would be impacted as a result of the unfolding scenario. Given the overall uncertainty, LTH was not at all sure about the severity of COVID and its impact. Hence, Keswani and the top management team started did scenario planning. Given the capital-intensive nature of hotel business where ARRs ${ }^{2}$ were contingent on demand (i.e. strong [weak] demand drove prices upwards [downwards]), top management of LTH

\footnotetext{
${ }^{2}$ Measures the average rate per available room. ARR may be calculated as ARR $=$ Total Room Revenue/Total Number of Occupied Rooms.
} 


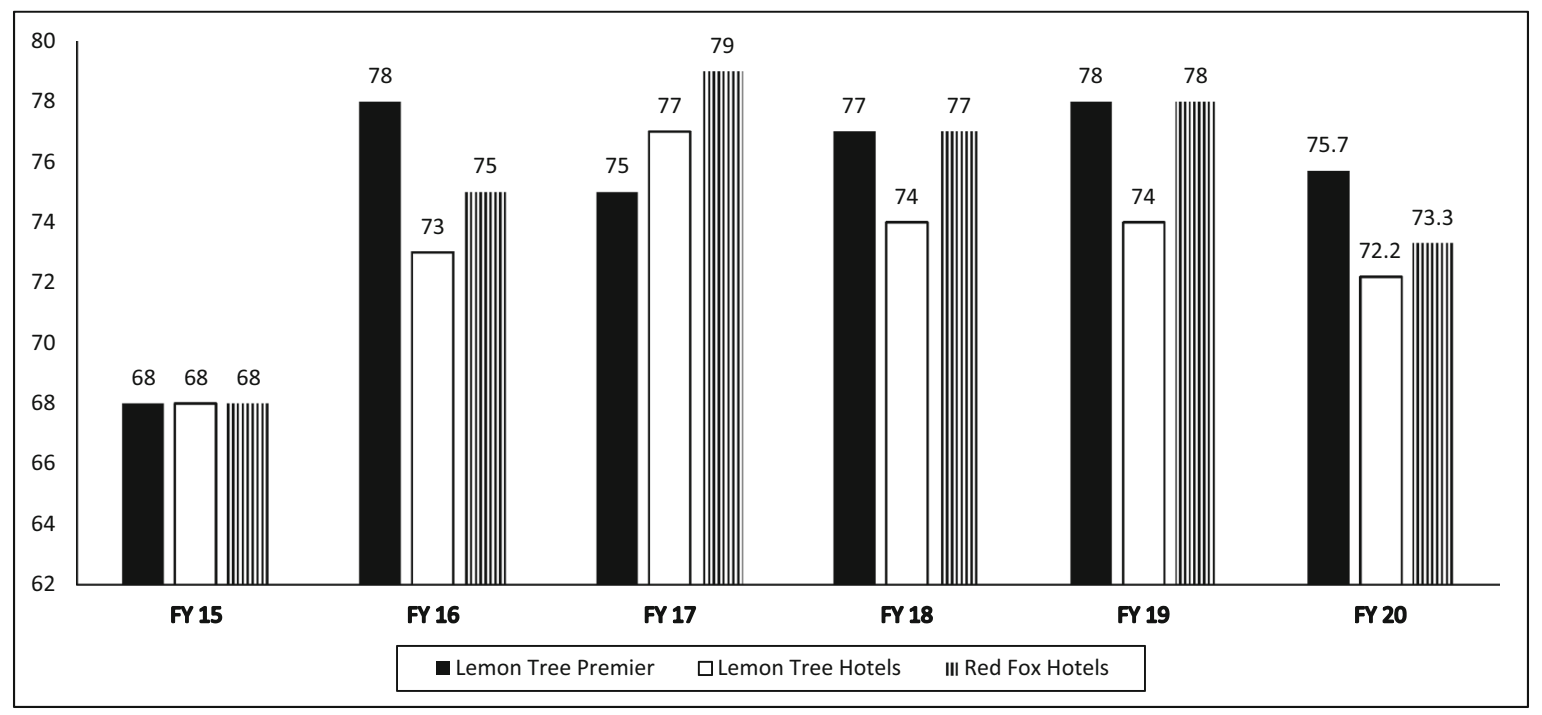

Fig. 1 Occupancy rate (\%) of LTP, LTH and RFH during FY15-FY 20. Source Adapted from Annual Report (2018-19) and Annual Report (2019-20), Lemon Tree Hotels. Retrieved 23 June 2021 from https://www.lemontreehotels.com/factsheet/

estimated that any point of time they would need a certain amount of cash to survive.

In order to survive during lockdown, LTH designed separate strategies to deal with decreasing revenues and manage the requirements/expectations of clients, guests and employees.

\section{LTH: steps taken during COVID}

Dealing with decreasing revenues

The top management team at LTH did scenario planning for possible drop in revenues. They planned for possibilities of revenue drop by $40 \%, 60 \%, 80 \%$ or one where a hotel would have to be shut partially due to zero occupancy. For each scenario, they drafted three plans so that if a specific plan failed to resolve the issue they could go for another option which they had thought of. Keswani noted:

"(during lockdown the) only one thing that we did which worked in our favour was (planning for) four scenarios: revenue drop of $40 \%, 60 \%$, $80 \%$ and if we shut our hotel. At those level of revenues with different combinations what cost do we need to hit with three or four priorities"
Policies/Lemon_Tree_Hotels_Limited_Annual_Report_2019_ 20.pdf, p.18. https://www.lemontreehotels.com/factsheet/ Policies/LTHLAnnualReport2018-19.pdf, p.10

(Leadership in the times of COVID-19 2020a; emphasis of the authors).

In order to control costs amidst decreasing revenues, Keswani also set up few priorities or boundary conditions: LTH would not lay off any existing employees because they believed that employees were their asset not their burden (Keswani, CMD Lemon Tree Hotels 2020a), and (b) no pay cuts for team members in the lower pay band (approximately 7000 employees) as COVID was the time when these employees needed the most support of the organization. Keswani noted:

"my top management colleagues said that we will take $66 \%$ salary cut for next 3 months. And the general manager and equivalent said that we will take 50\% and I said that I will take 100\%" (Leadership in the times of COVID-19 2020b).

Other major cost optimization measures included the controlling of electricity and water costs, raw material costs, overhead costs, etc. Keswani informed:

"We could permanently reduce $10 \%$ of our power expense plus we decided to go green so last year 5\% of total consumption of energy renewable but this year it will be $32 \%$... all put together we reckon there will be $20 \%$ saving in 
Table 1 Consolidated financial statements for LTH (All figures in Rs Cr.). Source https://stock-financials.valuestocks.in/fr/lemontree-hotels-quarterly-results, retrieved 09 July 2021

\begin{tabular}{|c|c|c|c|c|c|c|}
\hline Quarter ending: & $\begin{array}{l}\text { March } \\
2021\end{array}$ & $\begin{array}{l}\text { December } \\
2020\end{array}$ & $\begin{array}{l}\text { September } \\
2020\end{array}$ & June 2020 & $\begin{array}{l}\text { March } \\
2020\end{array}$ & $\begin{array}{l}\text { December } \\
2019\end{array}$ \\
\hline Net sales & 95.08 & 68.38 & 47.60 & 40.67 & 176.13 & 199.62 \\
\hline Total income & 98.38 & 72.73 & 57.00 & 45.61 & 177.28 & 203.47 \\
\hline Total expenditure & 66.56 & 48.30 & 39.29 & 36.31 & 112.19 & 118.42 \\
\hline Operating profit & 28.52 & 20.08 & 8.31 & 4.36 & 63.94 & 81.20 \\
\hline Other income & 3.30 & 4.36 & 9.40 & 4.94 & 1.15 & 3.85 \\
\hline $\begin{array}{l}\text { Profit before interest, depreciation and tax } \\
\text { (PBIDT) }\end{array}$ & 31.82 & 24.44 & 17.71 & 9.30 & 65.10 & 85.05 \\
\hline Interest & 44.52 & 47.53 & 49.72 & 48.69 & 49.49 & 45.88 \\
\hline $\begin{array}{l}\text { Profit before depreciation } \\
\text { and tax (PBDT) }\end{array}$ & -12.70 & -23.09 & -32.02 & -39.39 & 15.61 & 39.18 \\
\hline Depreciation & 26.11 & 27.34 & 27.02 & 27.09 & 27.74 & 22.69 \\
\hline Profit before tax & -38.81 & -50.43 & -59.03 & -66.48 & -12.13 & 16.48 \\
\hline Tax & -14.16 & -4.77 & -6.15 & -7.12 & 5.56 & 4.56 \\
\hline Profit after tax & -24.65 & -45.66 & -52.88 & -59.36 & -17.69 & 11.93 \\
\hline Net profit & -16.82 & -31.25 & -37.13 & -41.87 & -17.92 & 12.20 \\
\hline Equity capital & 790.42 & 790.34 & 790.33 & 790.33 & 790.31 & 790.25 \\
\hline Face value (in Rs.) & 10.00 & 10.00 & 10.00 & 10.00 & 10.00 & 10.00 \\
\hline Calculated EPS (annualized) & -0.85 & -1.58 & -1.88 & -2.12 & -0.91 & 0.62 \\
\hline No. of public share holdings & 58.72 & 58.72 & 54.62 & 54.48 & 54.48 & 54.48 \\
\hline$\%$ of public share holdings & 74.12 & 73.88 & 68.71 & 68.52 & 68.76 & 68.76 \\
\hline Operating profit margin $(\%)$ & 30.00 & 29.37 & 17.45 & 10.72 & 36.30 & 40.68 \\
\hline PBIDTM\% & 33.47 & 35.74 & 37.20 & 22.88 & 36.96 & 42.61 \\
\hline PBDTM\% & -13.36 & -33.77 & -67.27 & -96.85 & 8.86 & 19.63 \\
\hline Profit before tax margin (\%) & -40.82 & -73.75 & -124.02 & -163.47 & -6.89 & 8.26 \\
\hline Profit after tax margin (\%) & -25.93 & -66.77 & -111.10 & -145.96 & -10.04 & 5.97 \\
\hline
\end{tabular}

our power and fuel expenses" (Fireside chat between Mandeep Singh Lamba and Patu Keswani 2021a).

LTH did debt repayment on time. An important step LTH took was on-time or before-time payment to its MSME (micro-, small and medium enterprises) vendors. Keswani said:

"Larger companies are not paying them (MSMEs) because they are doing cashflow management by not paying them (MSMEs). So the second boundary condition was in our work system that we will pay all our MSME vendors within 30 days" (Keswani, CMD Lemon Tree Hotels (2020b).
Health and safety of guests

LTH was one of the first hotels Government of India approached for possibility of setting quarantine facilities for travellers. LTH was one of the first movers in this space. It also collaborated with Apollo Hospitals on "Project Stay I" (isolated) to accommodate asymptomatic guests and provide them safe and comfortable quarantine facilities (Lemon Tree Hotels Limited Annual Report 2019-20, p.11). They offered discounted rate for healthcare workers, police and paramilitary forces as well during lockdown (Annual Report 2019-20, Lemon Tree Hotels Limited, p.11). As on 17 May 2021, LTH's partnership with a number of hospitals under "Support by Lemon Tree" programme resulted in 1039 hotel rooms offered to 
various hospitals to take care of mild/asymptomatic COVID patients (BW Hotelier 2021). Some Lemon Tree hotels (in association with local administration) provided free packed meals to people who needed them during the lockdown. For example, Red Fox Hotel, Alwar worked with the City District Magistrate's office; Lemon Tree Premier, Mumbai provided free meals to Brihan Mumbai Municipal Corporation workers; Lemon Tree Premier, Dwarka, National Capital Region provided free breakfast to COVID patients at Civil Hospitals (BW Hotelier 2021).

Recounting the efforts of LTH during the second wave of the virus in India, Vikramjit Singh, President, Lemon Tree Hotels Ltd told:

"Our country is at a very crucial stage of the pandemic with the 2 nd wave impacting us across most cities of India. This dramatic increase in the number of positive cases, has resulted in an increasing need for quarantine accommodation for asymptomatic people who are either high risk or have been in contact with positive cases. From the beginning of this crisis, Lemon Tree has supported State governments in offering quarantine accommodation and we are now happy to partner with many leading hospitals, including Medanta, Apollo, Manipal, Kauvery and Mahavir. These partnerships are for specific hotels in Delhi, Gurugram, Bengaluru and Hyderabad. We believe it is extremely important for the private sector, especially hospitality, to play an active role in helping the Government control this pandemic" (Ray 2021).

At LTH, emphasis was on strict adherence to the guidelines of state and central governments such as social distancing guidelines, continuous sanitization, and wearing masks and gloves. In order to create healthy, safe and hygienic environment, LTH partnered with Diversey and launched the "Rest Assured" programme. Diversey provided LTH US EPA approved safe chemicals, support materials, videos and trainings to LTH employees so that they could run safer than before.

LTH installed sneeze guard in its offices so that employees could work freely and safely. In the first few days of the lockdown, the top management team was on phone calls almost 24/7 and the existing 300 SOPs were rewritten so as to take care of the health and safety of their guests and employees during COVID times. There was constant monitoring of the health of visitors and guests (temperature checking and checking for cold and cough) and constantly cleaned public areas of hotel such as entrance, lobby and washrooms. It also introduced digital platform for booking of hotel rooms and facilitation of check-in/check process. App-based system (QRestro App) was introduced for ordering from the menu and providing feedback. It allowed guests to access digital menus, order online and payments. LTH developed digital housekeeping rules and directories of services to ensure contactless services as much as possible. Overall, electronic payment was also encouraged in order to maximize guest's safety.

Keeping employees safe

LTH started sanitization and thermal screening before 15 March 2020. They took safety initiative in advance as they were serving quarantined guests. They ordered Personal Protective Equipment kits (PPE Kits) in order to ensure the safety of employees. Keswani stated:

"We (at LTH) will do whatever it takes when we are working in our hotels to ensure that we are not subject to infection" (Leadership in the times of COVID-19 2020c)

LTH provided proper accommodation to 2500 employees (along with employees with disability except Down's syndrome) so that they could stay in their hotel and no need to travel back at home, because travelling also had some risk of getting infected with the virus. Keswani noted:

"Broadly my (Keswani) big concern now and it will be true for nearly every company is...I have got a couple of thousand guys staying in our guest room as employees and...1200 guys staying in the hotel as guest...these guys and my colleagues have been working above and beyond without exception, now they want to go back home, which is fine, but now we need to replace them... But all these next 2000 guys come from homes... they wany to come back and how do we now ensure that they (employees coming back from home) do not have it (COVID- 19 infection) so that they do not infect each other nor do they infect our guests. We bring them back and for 15 days they will be quarantined in the hotel" (Leadership in the times of COVID-19 2020d). 
They also arranged quarantined centre for those employees who were back in the hotel after lockdown. They organized online training session for employees to accommodate them with new normal situation and tried their best to motivate employees through conference calls, video calls, etc. Special training sessions were also arranged for disabled employees in order to ensure their safety and security while working in the crucial situation. LTH introduced "Lemon Tree Cares" for employees which had the provision of covering vaccination expenses of employees and their families. LTH reimbursed all medical expenses during home quarantined days and for severe hospitalization cases (BW Hotelier 2021).

\section{Lessons from LTH's handling of the business during COVID}

\section{Transformational leadership}

Transformational leadership style is a style which transforms followers from within by making them more enthusiastic, energetic and passionate. Transformational leaders are truly inspirational as they can energize and motivate followers to change their overall perceptions to achieve the work goals. Drawing on Burns (1978) work on political leadership, Bass (1985) extended the concept for organizational settings and suggested four elements of transformational leadership: idealized influence, intellectual stimulation, inspirational motivation and individualized consideration.

Idealized Influence: Idealized influence refers to the way by which a leader influences the followers and acts a role model for his/her followers. Leaders who are high on idealized influence set a clear vision for their followers and create a psychologically secured environment which helps followers to achieve shortterm as well as long-term goals of the organization and thereby sustain for a longer span of time. Such leaders display a set of ideals and values consistently which influences followers. LTH leaders exhibit idealized influence during the pandemic. One aspect of LTH espoused mission included "Ensuring the well-being and self-worth of our colleagues, who are of the utmost importance to us". In a tough time like COVID, by setting up and adhering to an important boundary condition of no layoffs and no salary cut for lower level employees, LTH enacted its espoused mission. Moreover, LTH kept in regular touch with employees and cared for the safety and security of employees as well as their family members. Employees with Down's syndrome were asked to stay back at home as they were vulnerable to infection.

Intellectual Stimulation: Transformational leaders create an open and unique environment within the organization which encourages followers to innovate and come up with their own ideas to deal more effectively. This intellectually stimulating environment encourages followers to come out of their traditional ideas and comfort zone in order to develop a sustainable environment within the organization. LTH leaders successfully created intellectually stimulating environment during crisis period. They organized online meetings, webinars and workshops to provide necessary knowledge to employees and vendors. Keswani commented that the virtual medium of meetings implied that they had, at times, 100 people participating on a call and the traditional hierarchy was broken. People were feeling freer to contribute and offer ideas in the virtual medium. Keswani noted that he had, in fact, taken a step back and was impressed with the ingenuity of the staff at each of LTH's properties. Keswani, in April 2020, said (leadership in times of covid 2020e):

"I have 80 hotels all over India...I have also been amazed at the ingenuity they (General Managers of the hotels) are showing as micro CEOs...I find a lot of leadership is emerging...I have taken a step back actually and I am actually very pleased at seeing how some of our people even in the corporate office...even in nontraditional roles are doing stuff which is absolutely exceptional"

Keswani, in April 2020, also said (leadership in times of covid 2020f):

"Right now, about half our hotels are open and we have got a couple of thousand employees who have been staying in our hotels in guest rooms for the last one month... and I am amazed at their dedication...here's the amazing thing we discovered. The staffing per hotel is $40-45 \%$ of the staffing that was for the same hotel two months ago. But the occupancy of the operating hotels is still high...it is $60 \%$ which means $40 \%$ 
of our employees are doing $66 \%$ of the normal work"

Early into the lockdown, the top management team at LTH also demonstrated their readiness for be intellectually stimulated. They tried to find a way to not have to lay off very junior people. Keswani noted:

"Out of 8000 employees...7200 get only $40 \%$ of the total wages and 800 get the other about $50 \%$ and $10 \%$ is like general expense for welfare and so on. What we decided was that come what may, we would not lay off any of those 7200 . We would not fire them. We would pay them their salaries which means $40 \%$ of our fixed costs we would not touch. Therefore, to save money...everybody (in the Senior rings of the ladder) took a $50 \%$ pay cut in LemonTree and I took a $100 \%$ cut and in between some took a $70 \%$ cut"

Inspirational Motivation: The act of not laying off anyone during the difficult times coupled with the senior management taking a pay cut would have been inspiring and motivating for the staff. It would have strengthened employee morale and consequently enhanced commitment among followers. The leadership at LTH demonstrated "inspirational motivation" which would propel staff towards exceptional contributions going above and beyond the call of duty.

Individualized Consideration. Individualized consideration refers to the way by which the leaders take care of unique requirements of individuals. LTH provided individualized need-based solutions for different segments of employees. They organized specialized online training programme and webinars for opportunity deprived individuals. They also planned differently for different stakeholders. They tried to keep the business ecosystem alive by paying debt on time and caring for MSME (micro-, small and medium enterprises) vendors. In order to ensure safety and security of guests, they partnered with Diversey to launch "Rest Assured" programme in order to ensure safety and security within the hotel premise. The health and safety of employees were ensured through preventive measures in the early part of COVID and through vaccination.
Empathic perspective taking

It refers to capability of putting oneself in the shoes of others. It also refers to the ability to feel for others and understand others' perspectives. It is the most powerful tool during crisis period (Riess 2020). LTH showed perspective taking attitude by redefining the safety and security policies of guests, employees and vendors. LTH tried its best to provide safe and secured environment to all stakeholders. They tried to take care of guest's perspectives by introducing contactless services in order to gain trust of guests and ensure cleanliness even after pandemic they became the part of "Rest Assured" initiative (partnered with Diversey). They showed compliant attitude for noble cause by strictly adhering to the Government of India's lockdown principles. LTH took the perspectives of employees by adhering lockdown guidelines strictly. LTH introduced scheme for employees which had the provision to cover up vaccination expenses of employees and their families. LTH reimbursed all medical expenses during home quarantined days and for severe hospitalization cases as well. In addition to guests and employees, LTH leaders took broader perspective of the society and collaborated with hospitals and state government and provided rooms as quarantined centres and COVID hospitals. They also distributed foods packets to those who were in need during lockdown. As a part of social responsibility, they decided to accommodate quarantined guests and also provided accommodation to essential service providers such as doctors and paramedical staffs during lockdown.

\section{Relentless communication}

Effective communication is a crucial tool in any organization. In crisis period, effective and transparent communication plays a critical role in any organization. During crisis, effective communication and active listening play an important role (James 2020). LTH's persistent communication and active listening were the key of dealing with crisis situation. Leaders clearly and quickly communicated the information to the group via online meeting and conference calls so that rumours are not going to spread and create unnecessary tension in the group. They reviewed the crisis situation almost on a regular basis and communicated the information to the employees. They also 
maintained smooth communication with their vendors during crisis situation. During crisis situation, LTH not only communicated with employees and vendors but also with the larger community. They provided resources to the state government, medical service providers and needy people during quarantined and unlock period.

\section{Resilience and emotional stability}

Hougaard et al. (2020) pointed to the critical role of resilience in the face of crisis. Keswani (2020b) defined resilience as "the ability to absorb and bounce back in an adverse situation" and emphasized that "resilience is something absolutely vital for us (managers/leaders) to inculcate" (Patanjali Keswani, CMD Lemon Tree Hotels 2020c). LTH tried to be resilient during unprecedented times. This required emphasis on staying positive and focusing on aspects in LTH's control to reduce costs amidst decrease in revenue. The levels of scenario planning (i.e. for revenue drop of $40 \%, 60 \%, 80 \%$ and needed to shut the hotel) and three possible pathways (Plans A, B and C) for each scenario reiterated that the focus was on never leaving the eye of the ball. They calculated the weighted average of all these expectations based on 6 months, 12 months and 24 months, and they found that they needed so much of cash. They also calculated that in all these scenarios their expenses excluding the interest and principal repayment should be less than or equals to revenue. In so doing, LTH reacted quickly to the rapidly changing situation and planned strategies to deal with the unfolding crisis.

Emotional stability refers to a personality trait to remain stable and balanced in an adverse situation. It is one of the Big Five Personality Traits. The Big Five Personality trait model was originally developed by Fiske (1949) and later on expanded by Norman (1967), Smith (1967), Goldberg (1981) and McCrae \& Costa (1987). Leaders of LTH tried their best to find out the ray of hope even in a gloomy situation and planned different scenarios by keeping their heads cool and composed. They tried to retain their experienced employees and empower them so that they could utilized the knowledge and experience later on during post-corona era. In an unprecedented situation, LTH top management remained calm and focused on their priorities so that the organization can ride out the difficulties during the pandemic. The top management team under Keswani's stewardship teaches us the role of emotional stability as an important lesson for managing in a pandemic.

\section{Crisis management vs. crisis leadership}

James (2004) suggested that crisis leadership goes beyond crisis management as it is "not simply management of the situation but acts of leadership whereby the organization, the crisis, and the environment are considered holistically" (p. 7). She noted four aspects of crisis leadership: a corporate mindset that recognizes that one's organization can be affected due to events outside the organization's control, an effort to identify an organization's vulnerable areas, ability to make wise and rapid decisions, and to take courageous action. The case study of LTH provides examples about its top management's ability to make wise and quick decisions. Using virtual meetings, LTH top management sought inputs from all and even took a step back whenever required. Having taken care of the staff (no layoff and payment of salaries), they had inspired and fuelled the commitment of the staff. They allowed each hotel as a stand-alone unit to contribute efficiently. When approached by the Government of India for help with quarantine facilities, LTH swung into action. Overnight the almost 300 SOPs were rewritten to be applied in COVID times. The hotels continued to operate albeit at lower ARRs. There was also a learning in terms of the realization that going ahead, LTH could get affected by and needed to iron out its vulnerabilities in planning for the possibility of a similar disruption like COVID affecting its operations. LTH realized that hotels could run with a staffto-room ratio of 0.7 instead of the pre-COVID ratio of 1.0 (Kaushik 2021). Keswani also noted (fireside chat between Mandeep Lamba and Patu Keswani 2021b):

"I am the highest growth asset company in India. I am in CAPEX mode. I have a lot of debt which just got operationalized...(in future) I will build sufficient liquidity cushion. I will write down all my debt and as quickly as I can. I would also look at recycling cash because of the large number of assets we own. And I think the last is that I would revisit my risk management framework". 


\section{Conclusion}

LTH, a mid-priced hotel chain in India, opened its first hotel in 2004. In their journey from one hotel to more than 50 hotels (including managed and owned properties), they were also distinctive in a focus to providing opportunities for persons with disabilities and for opportunity deprived individuals. Like other organizations in the hospitality sector, LTH also encountered critical problems during the lockdown and unlock periods. The occupancy rate dropped drastically, future bookings were cancelled and ARRs plunged to low levels. This case study underscores the resilient approach of LTH leaders to deal effectively with the unprecedented situation. In order to serve the country during lock down and the second wave of COVID, LTH offered hotel rooms for quarantine and also partnered with major hospitals to provide facilities for healthcare professionals and mild or asymptomatic patients. In spite of adopting humanistic approach in dealing with pandemic, LTH is still struggling with the bigger question how long they will be able to continue with these services by sacrificing their revenues to a large extent. In adhering to its core values, LTH also took steps to focus on the health and safety of employees. Wherever possible, LTH tried to find avenues for and did, in fact, cut possible expenses. The relentless communication and transformational leadership displayed at LTH provide useful lessons for current/future managers and leaders.

We are also mindful of the limitations of this case study. The major limitation is that it is based on secondary data such as YouTube videos featuring LTH top management, articles and annual reports available on LTH website. Richer detail could have been possible if we had collected data through interviews of LTH top management/employees at various levels/customers. In drawing from secondary sources where LTH management discussed the steps they took to ride out the crisis, we cannot rule out the possibility that we did not get a window into the mistakes or unsuccessful initiatives, if any, at LTH during this period. We did, however, try to capture what LTH management mentioned as the key learnings from their handling of the crisis. Despite the above limitation, the present case study may be useful in understanding the innovative and resilient strategies need to be adopted by leaders in order to deal with an extremely unprecedented situation. We hope this case study inspires confidence and optimism for all of us to face adversity head on.

Funding The authors declare that they have no financial disclosure.

Data availability The present study is based on secondary data acknowledged in the reference section.

\section{Declarations}

Conflict of interest The authors declare that they have no conflict of interest.

\section{Appendix 1: Vision and mission of LTH}

Vision: The vision of LTH is to be India's largest and finest chain of upscale, mid-scale and economy hotels and resorts.

Mission:

- Ensuring the well-being and self-worth of our colleagues, who are of the utmost importance to us.

- Contributing to the community we live in and to India in general.

- Delighting our guests, whose comfort, safety, security and well-being is our main reason for being.

- Rewarding our stakeholders, whose trust motivates us to excel further.

- Maximizing the efficiency of our processes, to enable us to be the most cost-effective brand offering the greatest value, which our customers have every right to expect.

Core Values:

Health and Safety: We will always focus on ensuring the health, safety, security and well-being of all our stake holders including the communities within which we operate our business.

- Teamwork-We recognize that superlative performance is always the result of teamwork.

- Ownership-We always take responsibility for our actions.

- Respect and Empathy-We always exhibit respect and concern for colleagues, guests and partners.

- Integrity-We always maintain the highest standards of fairness and transparency in all our dealings. 
- Spirited Fun-We create an exciting and spirited work environment encouraging our colleagues to think freely.

- Excellence-We always drive excellence in what we do.

Source Lemon Tree Hotels-About Us, Management, Vision, Mission, Awards \& CSR, retrieved 30 July 2021 from https://www.lemontreehotels.com/ about-us.aspx

\section{References}

Amazing Workplaces Bureau (2019) Building an inclusive workplace, the lemon tree hotel way! Retrieved October 24, 2021 from https://amazingworkplaces.co/building-aninclusive-workplace-the-lemon-tree-hotel-way/

Annual Report (2019-20) Lemon tree hotels limited, p.5. Retrieved February 10, 2021 from https://www. lemontreehotels.com/factsheet/Policies/Lemon_Tree_ Hotels_Limited_Annual_Report_2019_20.pdf.

Annual Report (2019-20) Lemon tree hotels limited, p. 11. Retrieved February 10, 2021 from https://www. lemontreehotels.com/factsheet/Policies/Lemon_Tree_ Hotels_Limited_Annual_Report_2019_20.pdf

Annual Report (2019-20) Lemon tree hotels limited, p. 18. Retrieved February 10, 2021 from https://www. lemontreehotels.com/factsheet/Policies/Lemon_Tree_ Hotels_Limited_Annual_Report_2019_20.pdf.

Annual Report (2019-20) Lemon tree hotels limited, p. 33. Retrieved February 10, 2021 from https://www. lemontreehotels.com/factsheet/Policies/Lemon_Tree_ Hotels_Limited_Annual_Report_2019_20.pdf

Bass BM (1985) Leadership and performance beyond expectations. Free Press

Burns JM (1978) Leadership. Harper \& Row, New York

BW Hotelier (2018) Lemon tree hotels ranked the 12th best large workplace in Asia, 2018. Retrieved July 17, 2021 from http://bwhotelier.businessworld.in/article/LemonTree-Hotels-Ranked-the-12th-Best-Large-Workplace-inAsia-2018/27-04-2018-147589/" http://bwhotelier. businessworld.in/article/Lemon-Tree-Hotels-Ranked-the12th-Best-Large-Workplace-in-Asia-2018/27-04-2018147589/

BW Hotelier (2021) Lemon tree hotels introduces various initiatives amidst the COVID-19 pandemic. Retrieved June 27, 2021 from http://bwhotelier.businessworld.in/article/ Lemon-Tree-Hotels-introduces-various-initiatives-amidstthe-COVID-19-pandemic-/05-06-2021-392063/

Chandna H, and Basu M (2020) Modi announces 'Janata Curfew' on 22 March, urges for resolve, restraint to fight coronavirus. Retrieved October 21, 2021 from https:// theprint.in/india/modi-announces-janata-curfew-on-22march-urges-for-resolve-restraint-to-fight-coronavirus/ 384138/
Czeisler MÉ, Lane RI, Petrosky E, Wiley JF, Christensen A, Njai R et al (2020) Mental health, substance use, and suicidal ideation during the COVID-19 pandemic-United States, June 24-30, 2020. MMWR Morb Mortal Wkly Rep 69(32):1049-1057. https://doi.org/10.15585/mmwr. $\mathrm{mm} 6932 \mathrm{a} 1$

Dixit A, Marthoenis M, Arafat SMY, Sharma P, Kar SK (2020) Binge watching behavior during COVID 19 pandemic: a cross-sectional, cross-national online survey. Psychiatry Res 289:113089. https://doi.org/10.1016/j.psychres.2020. 113089

Economy (2020) COVID-19 blow: India's GDP shrinks a record $23.9 \%$ in first quarter of FY'21. Retrieved June 20, 2021 from https://thewire.in/economy/india-gdp-recordshrinks-fy21-q1-covid-19-lockdown

Fireside chat between Mandeep Singh Lamba and Patu Keswani (2021a) YouTube video, 18:11-18:33, posted by ANAROCK property, Retrieved July 31, 2021 from https://www. youtube.com/watch?v=MZJCn6vZO78

Fireside chat between Mandeep Singh Lamba and Patu Keswani (2021b) YouTube Video, 31:20-32:30, posted by ANAROCK property, Retrieved July 31, 2021 from https://www. youtube.com/watch?v=MZJCn6vZO78

Fiske DW (1949) Consistency of the factorial structures of personality ratings from different sources. J Abnorm Soc Psychol 44:329-344

Goldberg LR (1981) Language and individual differences. The search for universals in personality lexicons. In: Wheeler $\mathrm{L}$ (ed) Review of personality and social psychology, vol 2. Sage Publications, pp 141-165

Grover S, Sahoo S, Mehra A, Avasthi A, Tripathi A, Subramanyan A, Pattojoshi A, Rao GP, Saha G, Mishra KK, Chakraborty K, Rao NP, Vaishnav M, Singh OP, Dalal PK, Chadda RK, Gupta R, Gautam S, Sarkar S, Sathyanarayana, Rao TS, Kumar V, \& Janardran Reddy YC (2020) Psychological impact of COVID-19 lockdown: an online survey from India. Indian J Psychiatry, 62, 354-62. https://www.indianjpsychiatry.org/text.asp?2020/62/4/ 354/286222

Hougaard R, Carter J, \& Mohan M (2020) Build your resilience in the face of a crisis. Retrieved July 7, 2021 from https:// hbr.org/2020/03/build-your-resiliency-in-the-face-of-acrisis

James EH (2004) Crisis leadership. Product\# UV3243-PDFENG. Harvard Business School Publishing

James E (2020) There is really no roadmap': inside Wharton dean Erika James' first 90 days. Retrieved July 19, 2021 from https://technical.ly/philly/2020/10/19/wharton-deanerika-james-leadership-advice/

Kaushik M (2021). Lemon tree to open 20 new hotels without fresh hiring for 2 years. Retrieved March 12, 2021 from https:/www.businesstoday.in/latest/corporate/story/ lemon-tree-to-open-20-new-hotels-without-fresh-hiringfor-2-years-284169-2021-01-12

Keswani P, CMD Lemon Tree Hotels (2020a), YouTube video, 21:22-21:34, posted by IIMCreate from CEI at IIM Calcutta. Retrieved March 18, 2021 from https://www. youtube.com/watch?v=kgSZQmRV1kM

Keswani P, CMD Lemon Tree Hotels (2020b), YouTube video, 04:41-04:43, posted by IIMCreate from CEI at IIM 
Calcutta. Retrieved March 18, 2021 from https://www. youtube.com/watch? $\mathrm{v}=\mathrm{kgSZQmRV} 1 \mathrm{kM}$

Keswani P, CMD Lemon Tree Hotels (2020c), YouTube video, 04:24-04:28, posted by IIMCreate from CEI at IIM Calcutta. Retrieved March 18, 2021 from https://www. youtube.com/watch?v=kgSZQmRV1kM" https://www. youtube.com/watch? $\mathrm{v}=\mathrm{kgSZQmRV} 1 \mathrm{kM}$

Lal A (n.d) How India's lemon tree hotels has embraced disability inclusion to tackle the challenges of recruitment and retention in the hospitality sector. Retrieved October 24, 2021 from https://meaningful.business/how-indias-lemontree-hotels-has-embraced-disability-inclusion-to-tacklethe-challenges-of-recruitment-and-retention-in-thehospitality-sector/

Leadership in the times of COVID-19 (2020a) YouTube video, 34:03-34:22, posted by lemon tree hotels. Retrieved March 18, 2021 from https://www.youtube.com/watch?v= 6 YrewxXjDOo

Leadership in the times of COVID-19 (2020b) YouTube video, 38:25-38:37, posted by lemon tree hotels. Retrieved March 18, 2021 from https://www.youtube.com/watch?v= 6YrewxXjDOo

Leadership in the times of COVID-19 (2020c) YouTube video, 1:05:26-1:05:34, posted by lemon tree hotels. Retrieved March 18, 2021 from https://www.youtube.com/watch?v= 6 YrewxXjDOo

Leadership in the times of COVID-19 (2020d) YouTube video, 55:23-56:33, posted by lemon tree hotels. Retrieved March 18, 2021 from https://www.youtube.com/watch?v= 6 YrewxXjDOo

Leadership in the times of COVID-19 (2020e) YouTube video, 52:29-53:11, posted by lemon tree hotels. Retrieved March 18, 2021 from https://www.youtube.com/watch?v= 6YrewxXjDOo

Leadership in the times of COVID-19 (2020f) YouTube video, 54:04-54:41, posted by lemon tree hotels. Retrieved March 18, 2021 from https://www.youtube.com/watch?v= 6YrewxXjDOo

Lemon Tree Hotels (n.d) Lemon tree hotels-about us, vision, mission, values. Retrieved July 4, 2021 from https://www. lemontreehotels.com/about-us.aspx

McCrae RR, Costa PT Jr (1987) Validation of the five factor model of personality across instruments and observers. J Pers Soc Psychol 52(1):81-90
Money control (2020) Coronavirus lockdown has had disastrous impact on hospitality sector; govt support needed: Industry. Retrieved April 27, 2021 from https://www.moneycontrol. com/news/business/coronavirus-lockdown-has-haddisastrous-impact-on-hospitality-sector-govt-supportneeded-industry-5136101.html

Norman WT (1967) 2800 personality trait descriptors: normative operating characteristics for a university population. Ann, Arbor: MI: Department of Psychology, University of Michigan

Ray B (2021) Hotels turn into hospitals and extend care for patients. Retrieved May 7, 2021 from https://hospitality. economictimes.indiatimes.com/news/hotels/hotels-turninto-hospitals-and-extend-care-for-patients/82311302

Riess H (2020) Empathy in times of crisis. Retrieved July 22, 2021 from https://www.theberylinstitute.org/blogpost/ 947424/342524/Empathy-in-Times-of-Crisis

Smith GM (1967) Usefulness of peer ratings of personality in educational research. Educ Psychol Measur 27:967-984

Soni P (2021) Effects of COVID-19 lockdown phases in India: an atmospheric perspective. Environ Dev Sustain 23:12044-12055. https://doi.org/10.1007/s10668-02001156-4

The Indian Express (2020) Explained: how covid-19 has affected the global economy. Retrieved July 8, 2021 https://indianexpress.com/article/explained/explainedhow-has-covid-19-affected-the-global-economy-6410494/

UNESCO (2020) School closures caused by coronavirus (Covid-19). Retrieved June 152021 from https://en. unesco.org/covid19/educationresponse

Value Stocks (n.d.) LEMON TREE HOTELS quarterly results. Retrieved July 02, 2021 from https://stock-financials. valuestocks.in/fr/lemon-tree-hotels-quarterly-results

Word Health Organization (n.d) WHO coronavirus (COVID19) dashboard. Retrieved July 30, 2021 from https:// covid19.who.int/

Zandifar A, Badrfam R (2020) Iranian mental health during the COVID-19 epidemic. Asian J Psychiatry 51:101990. https://doi.org/10.1016/j.ajp.2020.101990

Publisher's Note Springer Nature remains neutral with regard to jurisdictional claims in published maps and institutional affiliations. 